\title{
Os desafios do passado a um toque
}

Pedro Paulo A. Funari*

FUNARI, P. P. A. Os desafios do passado a um toque. R. Museu Arq. Etn., 32: 33-40, 2019.

Resumo: $\mathrm{O}$ artigo trata dos desafios da digitalização das informações sobre o passado. Inicia-se com a apresentação de uma longa tradição de transmissão material e analógica das informações, desde a Antiguidade, tradição textual, imprensa, até a revolução informática e numérica. Apresentam-se, a seguir, as mudanças das últimas décadas no armazenamento e transmissão de informações, assim como crescente importância da realidade virtual no geral, e no que se refere à apresentação e tratamento do passado. No caso específico do mundo romano, multiplicaram-se os bancos de dados, tanto da tradição textual, como da imensa materialidade (inscrições, imagens, artefatos, construções e muito mais). Isso significa um acesso muito mais amplo e generalizado ao mundo romano. Outro aspecto refere-se à recriação virtual, que se amplia cada vez mais, tanto no meio acadêmico, como de divulgação. Isso gera questões epistemológicas pouco óbvias a respeito da diversidade interpretativa, na medida em que a ampliação das possibilidades construtivas virtuais leva à multiplicação de questionamentos sobre os modelos e pressupostos interpretativos. Talvez esse seja o maior desafio das novas tecnologias.

Palavras-chave: Humanidades digitais; Tecnologia; História; Arqueologia; Antiguidade.

\section{Introdução: a profundidade da transmissão}

transmissão das informações, de geração a geração, constitui um dos elementos basilares do ser humano. $\mathrm{O}$ mais antigo modo dessa prática pode ser avaliado pelos estudos com os primatas e a partir dos líticos, em particular na maneira como a gestualidade está na raiz da criação de tradições da transformação da pedra em uma variedade de artefatos.

$\left.{ }^{*}\right)$ Professor Titular do Departamento de História, Unicamp. Bolsista de produtividade em pesquisa do $\mathrm{CNPq}<$ ppfunari@ uol.com.br>
Não à toa aplica-se, muitas vezes, o nome de tradição à diversidade tipológica de artefatos pré-históricos, a enfatizar o papel dos gestos. Um estudioso como André Léroi-Gourhan (1965) irá enfatizar o quanto foi constitutivo do humano a reprodução de modos de fazer (Boeda et al. 1990). Esta foi, até agora, a fase mais duradoura da humanidade, definida, em termos mais largos, a partir dos primeiros hominídeos, ao menos desde 2.5 milhões de anos atrás (Semaw et al. 2003; Ko 2016). Essa maneira de transmissão, a mais antiga e mecânica, continua parte essencial da cultura humana, sempre ligada à produção e uso de artefatos necessários para a alimentação, em particular (Isaac 1978; Pelegrin 2004). 
A partir da utilização da fala, cujo uso não se sabe quando começou, este outro instrumento foi importante e pode imaginar-se, pela analogia antropológica, o quanto. A observação etnográfica de grupos humanos sem escrita mostra como essa transmissão oral é significativa e Jack Goody (1986) ressaltou bem, há décadas, as mudanças que a escrita trouxe à vida em sociedade, em particular em relação à transmissão. A oralidade não pode ser desvencilhada da musicalidade, de maneira a permitir a memorização e passagem de pequenos ou grandes volumes de informação a ser compartilhado por comunidades e por gerações (Patterson 2015). Rimas, repetições e cadências estavam e ainda estão, mesmo no contexto pós-moderno, na base da retenção e reprodução oral. Obras sem autoria definida, como a Ilíada, a Odisseia ou a Bíblia Hebraica (Antigo Testamento), mesmo imensas, tardaram séculos a serem transcritas. Foram conhecidas e memorizadas por centenas de anos, sem recurso ao texto escrito. Pode supor-se que seja possível preservar grande fidelidade, por muito tempo, por meio da transmissão oral, já que os primeiros registros escritos de muitas obras, como a Ilíada, a Odisseia ou a Bíblia Hebraica, encontram-se apenas em escritos datados de muitos séculos após sua difusão. Isso explica a importância da sonoridade e da musicalidade, que sempre permitiu a memorização, ainda que não seja este o único mecanismo de transmissão oral. Outros são de igual relevância, como é o caso da associação da gestualidade, das falas, do ambiente em que as histórias eram narradas, tudo isso garantia a perpetuação da ideia geral, da narrativa, da moral da história, como se diz, para além da memorização literal (Rosenberg 1987). Quem não lembra do filme Moana (2016)? O que importa, assim, é observar a capacidade de rememoração, às vezes com grande fidelidade, por via da repetição oral.

O uso da escrita, a partir do final do quarto milênio a.C. na Mesopotâmia e no Egito, trouxe mudanças que se aprofundaram, nos últimos seis mil anos. A escrita permitiu, em sociedades de classe e com conflitos internos e externos mais frequentes, que houvesse um registro a ser usado para garantir direitos, assim como defender prerrogativas, além de contribuir para a organização tecnológica ligada à agricultura e à vida urbana (Funari \& Poloni 2014). A escrita foi um apanágio de poucos até o século XX, mas sua influência foi muito importante, nesses milhares de anos, por diversos motivos. Embora dominada por poucos, a leitura permitia que o que estava escrito fosse lido e propalado de forma muito mais ampla. $\mathrm{O}$ escrito passou, em algumas circunstâncias, a adquirir aura ou sacra-

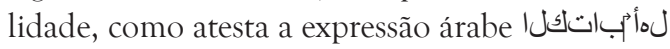
'Ahl al-Kitāb, que trata do escrito, das Escrituras, do Livro, do que foi vertido em escrita (neste caso, o Antigo e o Novo Testamentos, reconhecidos pelo Islã como escritos sagrados prévios ao Corão). A raiz semita ktb refere-se ao escrever, talvez com origem na noção de desenhar, rabiscar (Murtonen 1989:241), com os derivados de escrito, prescrito. Semelhante

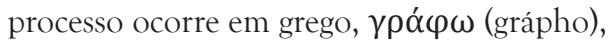
rabiscar, daí escrever, também em latim scribo, fazer um sulco, escrever, assim como em outros idiomas. Pode dizer-se que escrever e inscrever, tornar público, estão muito imbricados e, a despeito do analfabetismo, a leitura em voz alta atingia muito mais gente, como o caso, em particular, no mundo romano e seu hábito epigráfico (McMullen 1982).

A leitura silenciosa e o uso da escrita de idiomas que não podiam distanciar-se muito do passado, como no caso do latim, no Ocidente, e do grego, no Oriente, criaram uma separação entre a escrita e a oralidade das pessoas comuns, ainda que os vernáculos possam ter sido colocados por escrito em alguns lugares, como no caso do anglo-saxão, na Inglaterra, já no século VII, algo que só aconteceria cinco séculos depois, em outras partes do Ocidente. Pouco a pouco, o uso da escrita, em uma variedade de suportes materiais, foi em um crescente, com o uso do vernáculo (século XII), a imprensa (século $X V)$, certa ênfase na Reforma Protestante na leitura das Sagradas Escrituras (século XVI), a indústria, o estado nacional e a escola (século XIX). O século XX testemunharia a aceleração desse processo, com a generalização da leitura não apenas nos países ricos, como de renda média, como o Brasil (Ferraro 2011). Estavam dadas as condições do admirável mundo novo que adviria da realidade virtual e da conexão à outrance (híper conexão). 


\section{A revolução tecnológica e as reinvenções do passado}

A velocidade de mudança tecnológica acentuou-se nessas décadas do último século. A difusão por ondas de rádio e, depois, de televisão revolucionaram a comunicação, ao prescindirem, até mesmo, da alfabetização. Em muitos casos, foram essenciais para a difusão de línguas nacionais, frente à profusão de dialetos, algo que foi determinante para a generalização do domínio da escrita. Isso ocorreu mais cedo em países europeus como a Itália, mas avançou também em países asiáticos e africanos, já com o século XX mais avançado. Bollywood mostra como o uso de idiomas nacionais e a posterior alfabetização estiveram ligados, assim como foi o caso em muitos outros países, da Argélia a Angola. Isso constituiu um pressuposto cultural essencial para a popularização da hiperconexão no século XXI, na medida em que ainda se depende muito do domínio da escrita para acessar o mundo digital. $\mathrm{O}$ comando de voz promete mudar isso, mas até o momento, o digital e a conectividade dependeram e favoreceram a relação entre língua de comunicação nacional (ou subnacional), escrita e inserção nesse universo conectado. Houve, pois, uma conjunção de interesses políticos, culturais e tecnológicos, com o estado nacional (ou subnacional, em diversas situações concretas), mas sempre com o apoio oficial (nacional ou subnacional). Na Europa isso tem sido muito claro, como evidenciam os casos da Catalunha, da Croácia ou de Flandres, mas também nos outros continentes, em medidas variáveis.

As ciências históricas, em especial a Arqueologia, a História da Arte e a História, foram afetadas de modo muito particular. O passado, por definição, já passou e não existe senão no presente. Isto esteve sempre no cerne da preocupação com o que já não existe. No momento em que os humanos, lato sensu, enterram os seus mortos, desde ao menos os neandertais, a rememoração, no presente, do passado, esteve presente na vida social. Mesmo antes da nossa espécie, portanto. A narrativa do passado, no presente, gênero que só surgiria milhares de anos depois, estava já na raiz da sociabilidade. Heródoto, no século V a.C., com suas Histórias era o continuador de algo surgido muito antes. Soube explorar sentimentos profundos. Heródoto contava histórias de público e encantava, com narrativas às vezes mirabolantes, mas sempre atrativas. Tem havido e continua a haver uma permeabilidade inevitável entre História e histórias, explicitada por alguns, como Heródoto, Tito Lívio, Flávio Josefo e, em nossa época, Hayden White (1978). Não se pode desvencilhar a forma da narrativa histórica do relato histórico: a expessão res gestae engloba tanto as inefáveis "coisas acontecidas" como a narrativa por outrem dessas coisas (Moorehead 1995).

Toda narrativa sobre o passado depende de uma recriação no presente. Desde Tucídides, ao menos, houve a tentativa de excluir o relato do passado das possíveis falsificações derivadas da beleza da forma, quase como se a dificuldade e obscuridade da linguagem, a própria aspereza, pudesse distanciar o leitor das falsidades. Toda a História positivista, no século XIX, buscou esse distanciamento, em parte com o recurso à linguagem abstrusa. $\mathrm{O}$ próprio Tucídides não seguira à risca essa recusa da fruição, por parte da audiência, ainda que o possa ter feito de forma inconsciente, como atesta, entre outros, o discurso colocado na boca de Péricles (oração fúnebre, 2, 36-42). Também os modernos positivistas cediam à tentação, como mostra a descrição inicial de Leopold von Ranke (1834) do cristianismo em sua História do Papado em Época Moderna. Isso significa que, mesmo quando há um desejo explícito de evitar que o público seja seduzido pela forma da narrativa do passado, não se consegue escapar, de forma completa, disso.

No âmbito acadêmico, a Arqueologia viria a fornecer, desde sua constituição como disciplina histórica, no século XIX, dimensões novas para essas narrativas do passado, com seus edifícios, estátuas, imagens, objetos do quotidiano. As evidências materiais contribuíram para a difusão de perspectivas pós-positivistas, assim como para a interpenetração com outras disciplinas (Geografia, Filosofia, Antropologia, Sociologia, Biologia, Filologia, entre outras). Isso transparece na Escola dos Annales, mas também em Robin Collingwood (1946, arqueólogo, historiador, filósofo; Pinto 2017), Vere Gordon Childe (1942), Mikhail Rostovtzeff (1926; 1927), para 
citar apenas alguns. Subjetividade e o caráter narrativo do relato do passado firmam-se, com a difusão de verdadeiros best-sellers, livros de História voltados para leigos (Durant 1935/75). Depois da Segunda Guerra (1939-1945), a narrativa histórica difunde-se no rádio e, em seguida, na televisão, tanto no gênero ficção, como em documentários, com a contribuição do cinema (Carlan et al. 2015).

Isso tudo levou, ainda antes da ampla difusão da tecnologia digital, a uma explosão de narrativas históricas, aos lugares de memória e seus relatos ( $\mu$ ṽ 0 ot), como Pierre Nora (1984) já indicava. Com a revolução digital, isso chegaria ao que Neil Silberman (2016) chamou de explosão. Essa conectividade extrema (Claval 2014:128) permitiu em poucas décadas multiplicar tanto as narrativas sobre o passado como as possibilidades de criação de relatos alternativos (esse o sentido de $\mu \tilde{v} \theta 0$, mûthoi, mitos). A digitalização (Funari 2006; 2013) permitiu multiplicar de forma ilimitada as antigas maquetes, com a criação de mundos passados virtuais possíveis (e mesmo impossíveis), com um grau de verossimilhança tão alto que não se pode distingui-los senão com o recurso a modelos heurísticos, com o exame das diferentes perspectivas adotadas de forma explícita ou implícita. Mais que fidedignas, essas infinitas narrativas só podem ser tomadas como tomadas de posição (Habermas 1968).

\section{Os desafios do digital}

Os avanços das Humanidades Digitais (Fleming et al. 2017) têm sido grandes, em todas as áreas, com destaque, no que se refere ao passado, para a História, a Arqueologia e a Filologia Histórica (Nygren et al. 2014). As discussões epistemológicas em torno do próprio conceito de Humanidades Digitais têm tratado de aspectos como a mediação digital inevitável (Berry 2011), seu caráter multi e transdisciplinar (Machado 2018), ou mesmo a superação do termo digital, como propõe Berry (2014). Como quer que seja, as pesquisas acadêmicas em $\mathrm{Hu}$ manidades têm sido afetadas, de forma variada, profunda e benéfica: $\mathrm{O}$ acesso às publicações multiplicou-se; as bases de dados ampliaram-se muito; as parcerias facilitaram-se. Os estudos sobre o mundo romano têm se beneficiado, de forma direta, como se pode observar nos mais variados temas de estudo, da História Econômica (Rubi-Campillo et al. 2018) aos estudos dos assentamentos (Earl et al. 2016), sem descuidar da própria língua e literatura (Field 2016). Qualquer estudioso do mundo romano foi afetado pelo contexto digital, mesmo que de forma apenas indireta.

Por outro lado, a própria noção de veracidade está em questão no mundo digital (Rubin \& Vashchilko 2012). É possível editar sons e imagens, por meios numéricos, de modo que qualquer pessoa está sujeita à manipulação de comunicação (Schimdt 2018). No caso de autoridades, os mecanismos de verificação permitem, mesmo que com algum retardo, que se possa determinar a ação defraudadora, ainda que não se possa saber dos danos causados pela divulgação temporária da falsidade. No caso de indivíduos comuns, tanto mais será difícil desmascarar uma manipulação qualquer. No que se refere ao passado antigo, como o romano, a possibilidade de contrafação de imagens pode ser contraposta pelo uso de técnicas de detecção. Por outro lado, muito mais sutil será a discussão da reconstrução informática de boa-fé.

A confiança da modernidade na ciência objetiva e independente do observador tem sido posta em questão por todos os lados. $\mathrm{O}$ racionalista Karl Popper (1902-1994) destruiu a noção de certezas (Popper 1992), assim como outros, de Collingwood (1946) a Foucault (1971), a mostrar como, a partir de paradigmas diversos, a pós-modernidade tem colocado em cheque a possibilidade de narrativa neutra, certa, objetiva, indiscutível. Isso tem implicações profundas para a atualização do passado, agora sob o impacto das tecnologias digitais tão avassaladoras. Isso é tanto mais válido para a antiguidade romana, pela pujança dos vestígios arqueológicos e por sua imensa presença na tradição ocidental. Um locutor esportivo de rede de televisão brasileira não hesita em denominar o estádio olímpico de Roma, em partida de futebol, de "verdadeiro Coliseu", na expectativa de compreensão pelos torcedores. Roma está em cultos e missas toda semana, nas Bíblias, os livros mais presentes nos lares brasileiros, em 
particular no Novo Testamento. As procissões, telenovelas, filmes populares, tudo indica o conhecimento de massa, em particular, da materialidade romana: anfiteatros, roupas, termas (e hábitos, como banhos), vasos de cerâmica (como a tigela para lavar as mãos), entre muitos outros aspectos. Neste sentido, Roma está presente no imaginário ocidental, do Capitólio, em Washington, aos Tsares na Rússia, passando pelo Campo de Marte, em Paris.

Esse reconhecimento excepcional explica a significação particular do tema digital, no que se refere ao passado romano, presente em projetos acadêmicos, mas também na cultura popular, como em games. Neste último caso, que inclui filmes, seriados e uma infinidade de recreações, com apoio da tecnologia digital, não se está preocupado com a veracidade ou mesmo verossimilhança, na medida em que o foco está na diversão, recreação, não recriação, ficção, não História. Isso não significa total desconexão com a ciência, contudo, na medida em que, como lembra Richard Hingley (in: Vernant et al., 2005), entre outros, não se pode desvencilhar de todo a percepção difundida para os leigos e a compreensão dos estudiosos. Em particular, essas imagens costumam influenciar as crianças, que serão os adultos especialistas. Mas, no momento, talvez a possibilidade de reflexão menos especulativa esteja nos acadêmicos atuais, formados antes da digitalização universal, mas afeitos ao desafio da acomodação, por bem ou por mal, ao numérico.

A apresentação virtual do mundo romano é, quase por definição, uma tentação. Como não mostrar o Coliseu na sua inauguração? Como não apresentar um passeio virtual pela Domus Aurea? Mesmo cidadezinhas como Pompeia ou Gerasa (Jerash, Jordânia), com vestígios abundantes, ou modestos assentamentos, como Isca Silurum (Caerleon, País de Gales, Reino Unido), induzem a reconstruções digitais que transportam no tempo, até com o apoio de recursos 3D (e logo 4 D). Esses meios são de particular relevância em museus e em recursos didáticos, de modo a apresentar ao leigo, criança ou adulto, a experiência o quanto mais realista possível da visita ao passado. Quem resiste, leigo ou estudioso? Um passeio desses é irresistível.
A questão que se põe é epistemológica: como construir esse cenário virtual? $\mathrm{O}$ diretor de teatro, ou de cinema, sabe que de emoções se trata e se utiliza dos recursos tecnológicos disponíveis para seus desígnios (Chevitarese 2013). Os estudiosos a planear ou a aconselhar a montagem de uma criação virtual desse tipo dominam detalhes técnicos precisos e importantes, que podem insistir estejam presentes: uma moeda específica, um vaso cerâmico adequado, uma ânfora de tipo, época, aparência corretas... Uma Dressel 20, ânfora olearia bética, para retratar um recipiente vinário! Uma moeda de Nero na época de Augusto! Esses são os detalhes a que os especialistas estarão atentos e chocados, caso equívocos forem colocados. Esses são os comentários ubíquos a filmes, novelas, games ou o que seja, vindos daqueles que se dedicam ao estudo do passado, em particular os arqueólogos, mas também os outros especialistas: filólogos, historiadores, entre outros.

Esse aspecto da questão é de âmbito circunscrito e pode, em grande medida, ser verificado pelos diversos especialistas. Num filme religioso brasileiro, talvez não seja tão difícil evitar mostrar Jesus a usar uma moeda de Nero (posterior à sua morte) para retratar o "dai a César o que é de César” (Mt. 12, 13-17):

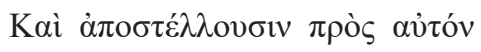

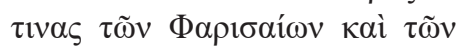

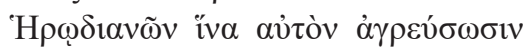

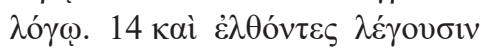

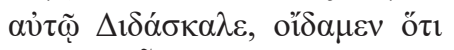

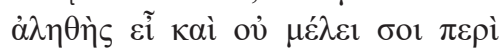

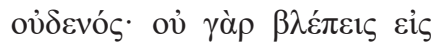
$\pi \rho \sigma^{\prime} \sigma \omega \pi \mathrm{ov} \dot{\alpha} v \theta \rho \omega ́ \pi \omega v, \dot{\alpha} \lambda \lambda \lambda^{\prime} \dot{\varepsilon} \pi^{\prime}$

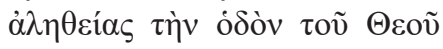

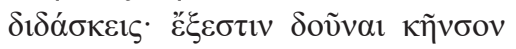

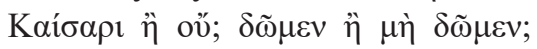

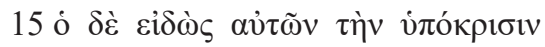

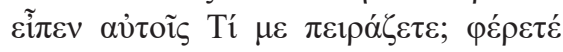

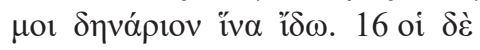

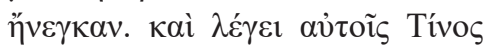

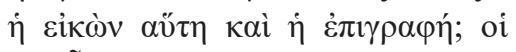

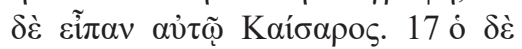

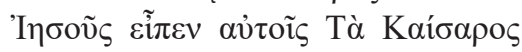

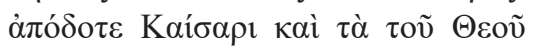

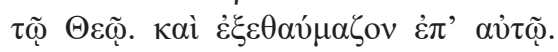


E enviaram-lhe alguns fariseus e partidários de Herodes, para que o apanhassem nalguma palavra. E aproximando, disseram-lhe: Mestre, sabemos que és verdadeiro, e não teme a opinião de ninguém, porque não olhas à aparência dos homens, mas ensinas segundo a verdade o caminho de Deus; é lícito dar o tributo a César, ou não? Daremos, ou não daremos? Então ele, conhecendo a sua hipocrisia, disse-lhes: Por que me tentais? Trazei-me um denário, para eu ver. E eles lhe trouxeram. E disse-lhes: De quem é esta imagem e inscrição? E eles lhe disseram: De César. E Jesus, respondendo, disse-lhes: Dai, pois, a César o que é de César, e a Deus o que é de Deus. E maravilharam-se dele (Tradução de Pedro Paulo A. Funari).

Mas, se essa correção do possível é possível, o que dizer do impossível? Como podemos tentar fidelidade de algo que não se pode saber se ocorreu? Mesmo o que ocorreu com certeza, como lutas de gladiadores, sobre as quais temos múltiplas evidências, inclusive em imagens da época, qual especialista teria como recriar, em 4 $\mathrm{D}$, um combate sequer? Como recriar a música tocada? Como retratar o culto? Isso sem chegar às diferenças de percepção, de pessoas cujos sentimentos não nos podem ser acessíveis senão por imaginação, tão subjetiva quanto somos diferentes.

Como estudiosos, este é um desafio particular: o passado a um toque (ou a um comando). Nada mais fácil, e cada vez mais ubíquo, que a experiência do passado por meios digitais, virtuais, num mundo de sensações. Nada mais difícil. A última tentação do estudioso, para parafrasear a Última Tentação de Cristo (Kazantzakis 1955; Scorsese 1988), é aventurar-se pelo que poderia ter sido, já que não se pode saber como foi. Trata-se de uma questão epistemológica: o passado não é senão recriação no presente, segundo certas premissas, de algo. Essas premissas são, pois, o cerne, daquilo que não pode deixar de preocupar o interessado no humano. As humanidades digitais nada podem ser, senão sob o crivo da dúvida, moto de sábios como

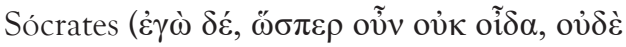
ớopar (Platão, Apologia de Sócrates, 21 d, "eu, como não sei nada, também estou certo de nada saber"), Descartes, Marx ou Kierkegaard, com o de omnibus dubitandum (tudo deve ser posto em dúvida). Como criar realidades virtuais, nestas circunstâncias?

A explicitação dos pressupostos parece ser o caminho para a diversidade de acessos oníricos, ou virtuais, ao passado. Nada mais em aparente contradição com as possibilidades de acesso real ao passado proporcionadas pela tecnologia, cuja imediatez parece tão sedutora. Nada mais difícil, talvez, do que mostrar o que não é possível, senão mostrar alternativas, narrativas diversas, todas em maior ou menor grau convincentes, a partir do parti pris de cada um, de épocas e circunstâncias, em constante mutação. A explicitação das premissas, da subjetividade inevitável da virtualidade, do passado a um toque ou comando de voz, pode ser o caminho da libertação, na aceitação da diversidade dos pontos de vista e percepções. O mundo romano oferece desafios tão maiores, quanto seus vestígios ubíquos podem induzir a certezas superficiais e ilusórias, sua pujança e mazelas a posições pouco críticas ou maniqueístas (mas quem há de negar a legitimidade dessa contraposição entre bem e mal?). A atualização do passado romano, no contexto das humanidades digitais, não pode prescindir da reflexão em si, do $\gamma \nu \omega \theta \iota$ $\sigma \varepsilon \alpha u \tau o ́ v$ (Pausânias, 10, 24, 1; conhece-te a ti mesmo) do oráculo délfico. Desafio dos mais difíceis, mas o mais essencial.

\section{Agradecimentos}

Agradeço a André Leonardo Chevitarese, Cláudio Carlan, Maria Isabel Fleming, Renato Pinto, Vagner C. Porto, José Remesal, Neil Silberman, Márcio Teixeira-Bastos. Menciono, ainda, o apoio institucional da Unicamp, Fapesp e CNPq. A responsabilidade pelas ideias restringe-se ao autor. 
FUNARI, P. P. A. The challenges of virtual past. R. Museu Arq. Etn., 32: 33-40, 2019.

\begin{abstract}
The paper deals with the challenges of digital representation access to the past. It starts by introducing a long-term tradition of material and analogic of data transmission, since ancient times, later manuscript copy, and printing reproduction up to the recent digital revolution. It follows by discussing the changes in the last decades in storing and transmission of information, including the growing importance of virtual reality in general and recreating the past in particular. Relating the Roman world, data banks are always more common, including ancient literature and the huge material evidence (inscriptions, images, artefacts, buildings and much more). This means a wider access to the Roman world. Virtual recreation increases all the time, in the media and in scholarship. This leads to tricky epistemological issues as far as virtual representations entail further questioning of interpretive frameworks. This may be the major challenge.
\end{abstract}

Keywords: Digital humanities; Technology; History; Archaeology; Antiquity.

\title{
Referências bibliográficas
}

Berry, D. M. 2011. The computational turn: thinking about the digital humanities. Culture Machine. Vol.12: 01-22.

Berry, D. M. 2014. Post-digital humanities: computation and cultural critique in the arts and humanities. Educause. Vol. 49, nº.3: 22-26.

Boëda, E; Geneste, J.-M.; Meignen, L. 1990. Identification de chaînes opératoires du Paléolithique ancien et moyen. Paléo. No.02: 43-88.

Carlan, C.U; Funari, P. P. A.; Funari, R. S. (Orgs.) 2015. O Cinema e o Mundo Antigo. 1. ed. Novas Edições Acadêmicas, São Paulo.

Chevitarese, A. L. 2013. Jesus no Cinema. Um Balanço Histórico e Cinematográfico entre 1905 e 1927. 1a . Ed. Kliné Editora, Rio de Janeiro.

Childe, V.G. 1942. What Happened in History. Penguin Books Ltd., Harmondsworth and New York.

Claval, P. 2014. História da Geografia. Edições 70, Lisboa.

Collingwood, R. 1946. The idea of history. Oxford University Press, Oxford.

Durant, W. (1935/1975) The story of civilization. Simon \& Schuster, Nova Iorque.

Earl, G. (et al.) 2016. Formal and Informal Analysis of Rendered Space: The Basilica Portuense. In: Bevan, A; Lake, M. (Eds.) Computional approaches to archaeological space. Routledge, London: 265-284.
Ferraro, A. R. 2011. A trajetória das taxas de alfabetização no Brasil nas décadas de 1990 e 2000. Educ. Soc. (Online). vol.32, n.117: 989-1013.

Field, A. 2016. An Automated Approach to Syntaxbased Analysis of Classical Latin. Disponivel em: https://journals.ub.uniheidelberg.de/index. $\mathrm{php} / \mathrm{dco} / \mathrm{article} / \mathrm{view} / 32315$. Acessado em: 16/04/2018.

Fleming, M. I.D; Teixeira-Bastos, M; Porto, V.C. 2017. Arqueologia Clássica e as Humanidades Digitais no Brasil. Cadernos do Lepaarq. (Universidade Federal de Pelotas), v.14. n.27: 10-28.

Foucault, M. 1971. L'Ordre du discours. Gallimard, Paris.

Funari, P. P. A. 2005. Repensando o mundo antigo. Volume I. Textos de: Jean Pierre Vernant e Richard Hingley. In: Textos Didáticos. Publicações do IFCH/Unicamp. v. 47: 1-70.

Funari, P. P. A. 2013. Aspectos da gestão de acervos em bibliotecas na era digital. Mimesis. (Bauru), v. 28: 23-38.

Funari, P. P. A. 2006. Gestão, preservação e acesso a documentos digitais: patrimônio cultural e diversidade. Cadernos do CEOM (UNOESC). v.18. n.22: 213-229.

Funari, P. P. A.; Poloni, R. J. S. 2014. Arqueologia Urbana: trajetória e perspectivas. Revista do Arquivo Municipal (São Paulo), v. 205: 137-154. 
Mcmullen, R. 1982. The Epigraphic Habit in the Roman Empire. The American Journal of Philology. Vol. 103, No. 3: 233-246.

Murtonen, A. 1989. Hebrew in its western Semitic setting. Brill, Leiden.

Goody, J. 1986. The Logic of Writing and the Organisation of Society. Cambridge University Press, Cambridge.

Habermas, J. 1968. Technik und Wissenschaft als Ideologie. Suhrkamp, Frankfurt.

Isaac, G. 1978. The Food Sharing Behavior of Protohuman Hominids. Scientific American. v.238, n.4: 90-108.

Ko, K. H. 2016. Origins of human intelligence: The chain of tool-making and brain evolution. Anthropological Notebooks. v.22, n.1: 5-22.

Leroi-Gourhan, A. 1965. Le Geste et la parole. (Vol.1: Technique et langage; Vol.2: La mémoire et les rythmes). Ed. Albin Michel, Paris.

Machado, M. 2018. A teoria da antropologia digital para as humanidades digitais. Revista Z Cultural. UFRJ. v. 02. s/p.

Moorehead, J. D. 1995. Compromising the Hearsay Rule: The Fallacy of Res Gestae Reliability. Loyola of Los Angeles Law Review. V.29 (November): 203-246.

Nora, P. 1984. Les Lieux de mémoire. Gallimard, Paris.

Nygren, T; Foka, A; Buckland, P. 2014. The Status Quo of Digital Humanities in Sweden: Past, Present and Future of Digital History. H-Soz-Kult. Disponível em: www.hsozkult.de/debate/id/diskussionen-2402.

Patterson, E. E. 2015. Oral Transmission: A Marriage of Music, Language, Tradition, and Culture. Musical Offerings. vol.6, nº1, Article 2: 35-47.

Pelegrin, J. 2004. Sur le milieu intérieur d'André Leroi-Gourhan et l'analyse de la taille de pierre au Paléolithique. In: Audouze, F; Schlanger, N. (Eds.) Autour de l'homme: contexte et actualité d'André Leroi-Gourhan. Editions APDCA: Antibes: $149-162$.

Pinto, R. 2017. Uma morte muito exagerada: Robin G. Collingwood e a 'romanização' da
Bretanha Romana. Revista Heródoto. Unifesp. v. 2: $522-543$.

Popper, K. 1992. In search of a better world. Routledge, London.

Rosenberg, B.A. 1987. The Complexity of Oral Tradition. Oral Tradition. 2/1: 73-90.

Rostovtzeff, M. 1926. A History of the Ancient World: Volume I. The Orient and Greece. Oxford: Clarendon Press.

Rostovtzeff, M. 1927. History of the Ancient World: Volume II. Rome. Oxford: Clarendon Press.

Rubin, V. L.; Vashchilko, T. 2012. Extending information quality assessment methodology: A new veracity/deception dimension and its measures. Proc. Am. Soc. Inf. Sci. Technol. vol. 49, no. 1: $1-6$

Rubio-Campillo, X.; Montanier, J. M.; Rull, G.; Bermúdez L. J. M; Moros Díaz, J.; Pérez González, J.; Remesal Rodríguez, J. 2018. The ecology of Roman trade. Reconstructing provincial connectivity with similarity measures. Journal of Archaeological Science. Volume 92: 37-47.

Schmidt, S. 2018. Al-based fake videos pose the latest threat to what we perceive as reality - and possibly our democracy. Disponível em: https://www.pri. org/stories/2018-03-18/ai-based-fake-videos-pose-latest-threat-what-we-perceive-reality-and-possibly-our. Acessado em: 16/04/2018.

Semaw, S.; Rogers, M. J.; Quade, J.; Renne, P. R.; Butler, R. F.; Dominguez-Rodrigo, M.; Stout, D.; Hart, W. S.; Pickering, T.; Simpson, S. W. 2003. 2.6-Million-year-old stone tools and associated bones from OGS-6 and OGS-7, Gona, Afar, Ethiopia. J. Hum Evol. vol.45 (2): 169-177.

Silberman, N. 2016. Discovering Authenticity, Getting to the heart of places that matter. Disponivel em: http://www.coherit.com/blog/ author/neil/.

Von Ranke, L. 1834-1836. Die römischen Päpste in den letzten vier Jahrhunderten. White, $\mathrm{H}$. 1978. Tropics of Discourse: Essays in Cultural Criticism. The Johns Hopkins University Press, Baltimore. 